\title{
Motor Torque Estimation and Security Control for Electric Vehicles (EV) Based on Parameters Feature Extraction
}

\section{Peng Zhiyuan ( $\nabla$ cqupzy@163.com )}

Chongqing Changan Automobile Co Ltd https://orcid.org/0000-0002-7496-721X

\section{DU Changhong}

Chongqing Changan Automobile Co Ltd

\section{ZHOU Anjian}

Chongqing Changan Automobile Co Ltd

LIU Li

Chongqing Changan Automobile Co Ltd

CHEN Yang

Chongqing Changan Automobile Co Ltd

\section{CHEN Jian}

Chongqing Changan Automobile Co Ltd

\section{Peng Qianlei}

Chongqing Changan Automobile Co Ltd

\section{Original Article}

Keywords: Electric vehicle, torque estimation, security control, failure state, parameters feature

Posted Date: April 8th, 2021

DOl: https://doi.org/10.21203/rs.3.rs-327531/v1

License: (a) This work is licensed under a Creative Commons Attribution 4.0 International License. Read Full License 


\title{
Motor Torque Estimation and Security Control for Electric Vehicles (EV) Based on Parameters Feature Extraction
}

\author{
PENG Zhiyuan ${ }^{1 *}$ DU Changhong ${ }^{1,2}$ ZHOU Anjian ${ }^{1,2}$ LIU Li $^{1,2}$ CHEN Yang ${ }^{1}$ CHEN Jian ${ }^{1}$ Peng Qianlei ${ }^{1}$
}

(1.Chongqing Changan New Energy Vehicle Technology Co., Ltd, Chongqing 400020, China)

(2.Chongqing University, Chongqing 400030, China)

\begin{abstract}
Motor as well as its controller plays an important role in driving electric vehicle. As sole power device, it is closely related with actual torque accuracy to make sure security during EV driving. Due to complex controlling system for motor, there are some random failures of hardware and software which can bring a series of unexpected risks for EV acceleration or deceleration. A novel method based on motor parameters feature is proposed to estimate motor torque according to torque estimation scheme based on parameters feature extraction for three-phase of volts and currents. Additionally, Quality Factor $(Q F)$ and confidence coefficient are also adopted to judge whether motor estimation torque is reasonable or not and motor failure torque is limited to prohibit output by setting fault flag in controller software. Finally, test bench is built to estimate torque accuracy compared with actual test value and verify security control strategy at the state of failure modes, test results show that estimation torque accuracy is within $\pm 5 \mathrm{Nm}$ which is compared with actual test torque and motor system can effectively come into security state from failure state by security control strategy designed in this paper.
\end{abstract}

Index Terms-Electric vehicle, torque estimation, security control, failure state, parameters feature

\section{Introduction}

With increasing awareness of energy conservation and environmental protection all over the world, government and automobile enterprises put much focus on electric vehicle [1]-[4]. Permanent Magnet Synchronous Motor (PMSM) is widely used in electric vehicle due to its wide range of higher efficiency and higher power density [5]-[8]. Currently, efficiency and power density can be increased with integration level improvement for motor system. Meanwhile, system failure risk is gradually raised due to deeper integration complexity. Motor system failure will bring a series of hazard to pedestrians or passengers, additionally great business profits and brand loss which is caused by motor system failure will enforce automobile enterprises all over the world to take effective measurement to avoid hazard reasonably and put motor function security in the first place [9].

Motor system failure puts much focus on abnormal torque output to drive electric vehicle. Torque failure which brings electric vehicle to unexpected acceleration or deceleration state includes unacceptable torque error and torque opposite direction chiefly. Therefore, it is very important to estimate motor actual torque accurately and cut off torque output within proper time to make sure no generation of unexpected acceleration or deceleration when motor system comes into software or hardware failures during electric vehicle running [10].

Obviously, it is significant to build a method and architecture scheme to estimate motor actual torque precisely, then the protection strategy of motor torque security should be designed to ensure vehicle from hazard running state to security state when motor torque comes into serious failure state. Therefore, the study on how to estimate torque and take security control is concerned among automobile enterprises and scientific research institution.

Zhao [11] designs a security monitoring model of torque control based on the torque control strategy for pure electric vehicles and the security analysis methods in international standard ISO 26262, and the security mechanism design ensured the system transition into safe state when failures were detected. Wu [12] introduces basic method of Hazard Analysis and Risk Assessment (HARA) related with the functional security standard, then the security goal and Automotive Security Integration Level (ASIL) of EV Motor Control Unit (MCU) have been derived according to HARA and the implementation method of 
function monitoring level was proposed through the analysis of function security architecture. Song [13] studies the fault modeling of MCU is carried out with fault tree analysis, then the software architecture of motor function security are designed based on the idea of layering and modularization. Sabbella [14] develops the functional security concept and technical security concept of related security functions of MCU such as torque monitoring and also design the MCU technical security requirements which refines the functional security concept considering system architecture and three-level security monitoring architecture.

According to previous summary, there are common analysis and development process based on ISO 26262 in recent research all over the world. The accuracy of classic torque estimation based on current method of $d$ and $\mathrm{q}$ axis coordinate is easily affected by motor of other inherent parameters such as inductance of $d$ and $\mathrm{q}$ axis coordinate as well as flux linkage. Additionally, these parameters which is adopted to estimate torque may cause invalid fault torque if there is no consideration of confidence coefficient for each parameter. Therefore, parameters as little as possible should be adopted to develop algorithm to monitor motor actual torque effectively after confidence coefficient and QF closely related with estimation torque reliability are evaluated.

\section{The Process of Function Security Development}

Due to increasing with new function development and integration complexity, software and hardware may cause greater risks of random motor system faults [15]. Therefore, a series of effective security mechanism and protection measurements should be applied to avoid these serious hazard based on ISO 26262 national standard [16]-[17]. Firstly, risks and hazards related with main driving functions for power system should be analyzed and identified according to fig.1. Then, function security requirement and function security goal are figured out by analyzing the level of exposure (E), severity (S) as well as controllability (C), next technical security requirements are decomposed into hardware and software requirements based on the

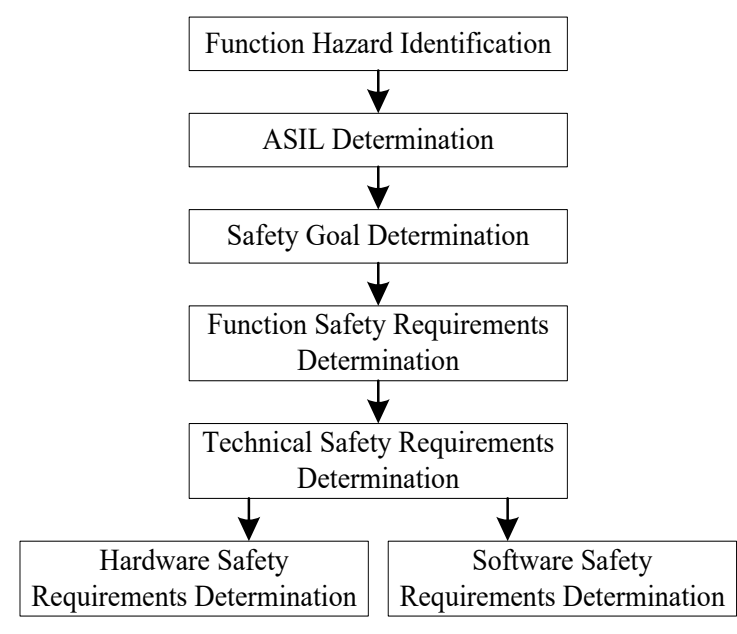

Fig.1 The process of function security development

determination of security goal. Lastly, a novel algorithm of torque estimation is proposed in the phase of software security requirement determination based on parameters feature extraction for three-phase of volts and currents.

\section{The Concept Design of Motor Torque Security}

The aim of concept design is to ensure function items and usage scenario of electric vehicle, analyze failure risks as well as figure out security goals and solution measurements for each risk [18].

\subsection{Usage Scenario Analysis for Function Item}

There are three main function items including propulsion, braking and parking based on requirements from vehicle to motor. For propulsion and braking function items, when motor system receives requirement torque and operation mode form Vehicle Control Unit (VCU), electric vehicle may run forward or backward direction at different road states such as icy road, wet and slippery pavement as well as dry pavement and so on. For parking function items, when MCU receives no requirement of torque and power down mode form $\mathrm{VCU}$, electric vehicle comes into stationary state.

\subsection{Hazard Analysis and Risk Assessment (HARA)}

To make sure pedestrian's security, when failure function implements because of software and hardware failures, it is necessary to consider and finish hazard analysis as well as risk assessment in Tab.1 and take a series of effective measurements to eliminate unreasonable torque execution which will suddenly bring unexpected acceleration or deceleration [19]. 
Tab.1 The table of hazard analysis and risk assessment for motor system

\begin{tabular}{|c|c|c|c|c|c|c|c|c|}
\hline Fault Types & Usage Scenario & Risk Types & $\mathrm{E}$ & $\mathrm{S}$ & $\mathrm{C}$ & $\begin{array}{c}\text { Security } \\
\text { Level }\end{array}$ & Security Goal & Security State \\
\hline Unexpected torque output & Parking, creeping & Crash, Harm & E4 & S3 & $\mathrm{C} 2$ & $\mathrm{C}$ & Prohibit output torque & No output torque \\
\hline Excessive torque deviation & $\begin{array}{l}\text { Accelerating, decelerating or } \\
\text { constant speed }\end{array}$ & Crash, Harm & E3 & S3 & $\mathrm{C} 3$ & $\mathrm{C}$ & $\begin{array}{l}\text { Output torque less than } \\
\text { requirement torque }\end{array}$ & No output torque \\
\hline Reverse torque direction & $\begin{array}{l}\text { Creeping, decelerating or } \\
\text { reversing }\end{array}$ & Crash, Harm & E4 & S3 & $\mathrm{C} 2$ & $\mathrm{C}$ & $\begin{array}{l}\text { Torque direction same } \\
\text { with requirement torque }\end{array}$ & No output torque \\
\hline $\begin{array}{l}\text { Three-phase currents or } \\
\text { voltages check faults }\end{array}$ & $\begin{array}{l}\text { Run with electromagnetic } \\
\text { interference, starting }\end{array}$ & Power Lose & E3 & $\mathrm{S} 3$ & $\mathrm{C} 3$ & $\mathrm{C}$ & Prohibit output torque & No output torque \\
\hline
\end{tabular}

After usage scenario is clear, function security levels for motor system are defined as 4 layers from ASIL A to ASIL D by setting indicator parameters $\mathrm{E}, \mathrm{S}$ and $\mathrm{C}$ of function risks which comes from actual usage scenario for electric vehicle [20]-[21]. E includes 5 layers from E0 to E4 increasing with hazard exposure probability level. S includes 4 layers from S0 to S3 increasing with hazard severity level. C includes 4 layers from $\mathrm{C} 0$ to $\mathrm{C} 3$ decreasing with hazard controllability level. Function security level and goal are evaluated and confirmed by combining actual usage scenario and road situation with hazard occurrence of $\mathrm{E}, \mathrm{S}$ and $\mathrm{C}$ [22].

\section{The Design of Motor Torque Estimation and Security Control}

The normality of motor torque operation plays a key factor for electric vehicle security based on HARA analysis. Therefore, it is vital to design reasonable and effective architecture scheme of motor torque estimation. Here, three-tier architecture scheme of torque estimation is designed including input level, control level and output layer in Fig.2.

\subsection{Input Signal Process}

In input layer, three-phase volts and currents are obtained with filtering process as important parameters for motor torque estimation [23]. Additionally, the signal of rotary transformer angle is adopted as a redundancy design to calculate motor speed when three-phase volts and currents go to be fault.

\subsection{Confidence Flag Evaluation}

In order to obtain reliable calculation parameters, it is necessary to check the confidence flag for three-phase volts and currents before they are used to estimate motor torque. Here, three-phase volts and currents are transformed into constant amplitude volts $\left(U_{\alpha}, U_{\beta}\right)$ and currents $\left(I_{\alpha}, I_{\beta}\right)$ of $\alpha$ and $\beta$ axis as equation (1).

$$
\left\{\begin{array}{c}
U_{\alpha}=U_{u} \\
U_{\beta}=\frac{\sqrt{3}}{3}\left(U_{v}-U_{w}\right) \\
I_{\alpha}=I_{u} \\
I_{\beta}=\frac{\sqrt{3}}{3}\left(I_{v}-I_{w}\right)
\end{array}\right.
$$

Where $U_{u}, U_{v}$ and $U_{w}$ are three-phase volts respectively. $I_{u}, I_{v}$ and $I_{w}$ are three-phase currents respectively.

Then, the sum of squares for constant amplitude volts $\left(U_{\alpha}, U_{\beta}\right)$ is considered to be greater than that of minimal constant amplitude volts and also the change rate of electrical angle is not beyond the maximal value

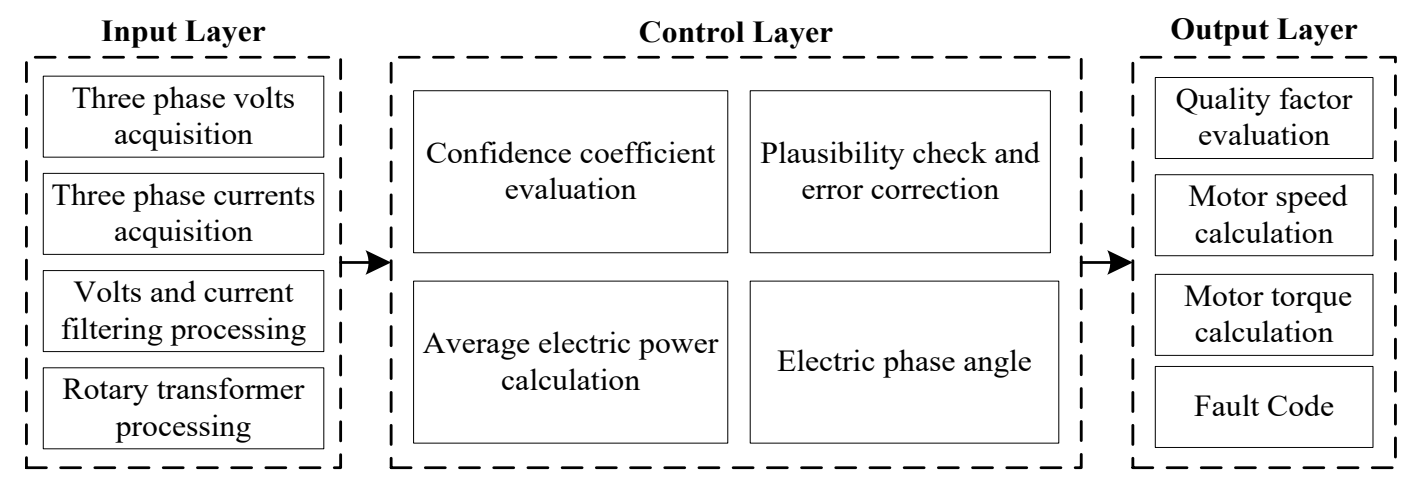

Fig. 2 The architecture scheme of torque monitoring 
when three-phase volts and currents is normal. Therefore, confidence flag of volts $\left(B_{U}\right)$ are obtained as below. Similarly, the judgment logic of confidence flag for currents $B_{I}$ is same with $B_{U}$.

1) $U_{\alpha}^{2}+U_{\beta}^{2}<U_{\min }^{2}$ or $\Delta \varphi>\Delta \varphi_{\max }, B_{U}=0$.

2) $U_{\alpha}^{2}+U_{\beta}^{2}>U_{\min }^{2}$ and $\Delta \varphi<\Delta \varphi_{\max }, B_{U}=1$.

Where $U_{\min }$ is the minimal constant amplitude volts, $\Delta \varphi$ is the rate of change for electrical angle between a sample time interval, $\Delta \varphi_{\max }$ is the maximal rate of change for electrical angle.

\subsection{Plausibility Check and Deviation Correction}

Kirchhoff law for three-phase volts and currents is used to judge whether 'Null Shift' that affects $Q F$ meets requirement or not. Volts and currents of $Q F_{(U)}$ and $Q F_{(I)}$ are set to 2 when it meets the requirement of inequation (2), otherwise $Q F_{(U)}$ and $Q F_{(I)}$ are set to 0 irreversibly.

$$
\left\{\begin{array}{c}
U_{u}+U_{v}+U_{w}<U_{l i m} \\
I_{u}+I_{v}+I_{w}<I_{\text {lim }}
\end{array}\right.
$$

Where $U_{\text {lim }}$ and $I_{\text {lim }}$ are the deviation limit of three-phase sum of volts and currents.

If the sum of three-phase volts and currents is not exceed to the limit value, deviation correction of volts and currents for each phase is just need as equation (3).

$$
\left\{\begin{array}{c}
\left(U_{u}, U_{v}, U_{w}\right)_{\text {upd }}=\left(U_{u}, U_{v}, U_{w}\right)-\Delta U_{c o r} \\
\left(I_{u}, I_{v}, I_{w}\right)_{u p d}=\left(I_{u}, I_{v}, I_{w}\right)-\Delta I_{c o r} \\
\Delta U_{c o r}=\left(U_{u}+U_{v}+U_{w}\right) / 3 \\
\Delta I_{c o r}=\left(I_{u}+I_{v}+I_{w}\right) / 3
\end{array}\right.
$$

Where $\left(U_{u}, U_{v}, U_{w}\right)_{u p d}$ and $\left(I_{u}, I_{v}, I_{w}\right)_{u p d}$ are updated vector value of three-phase volts and currents. $\Delta U_{\text {cor }}$ and $\Delta I_{\text {cor }}$ are correction value of three-phase volts and currents.

Additionally, plausibility check in equation (3) is also adopted to consider $Q F$ as below. Volts and currents of $Q F_{(U)}$ and $Q F_{(I)}$ are set to 2 when it meets the requirement of inequation (4), otherwise $Q F_{(U)}$ and $Q F_{(I)}$ are set to 0 irreversibly.

$$
\left\{\begin{array}{c}
U_{\text {pha_min }}<\left[U_{u}, U_{v}, U_{w}\right]<U_{\text {pha_max }} \\
I_{\text {pha_min }}<\left[I_{u}, I_{v}, I_{w}\right]<I_{\text {pha_max }}
\end{array}\right.
$$

Where $U_{\text {pha_min }}$ and $U_{\text {pha_max }}$ are the minimal and the maximum volts for each phase. $I_{\text {pha_min }}$ and $I_{\text {pha_max }}$ are the minimal and the maximum currents for each phase respectively.

4.4 Motor Speed Calculation and Average Power

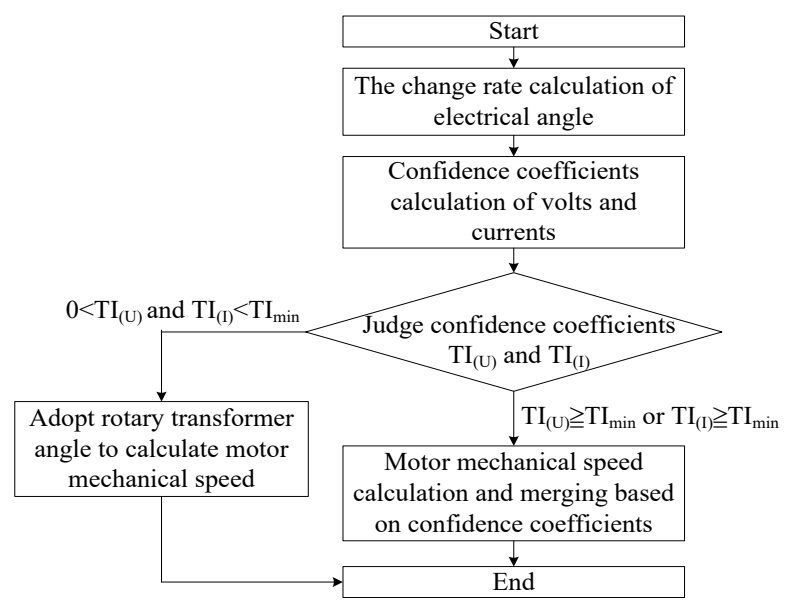

Fig. 3 The calculation process of motor mechanical speed

Motor mechanical speed is obtained based on constant amplitude volts $\left(U_{\alpha}, U_{\beta}\right)$ and currents $\left(I_{\alpha}, I_{\beta}\right)$ as well as confidence coefficients $\left(B_{U}, B_{I}\right)$ in the process of fig. 3 .

First of all, the change rate of electrical angle during a sample time interval $\Delta t$ is calculated by constant amplitude of volts and currents in equation (5) as below.

$\left\{\begin{array}{c}\Delta \varphi_{U}=\left(\arctan U_{\alpha} / U_{\beta}\right)^{\prime}-\left(\arctan U_{\alpha} / U_{\beta}\right) \\ \Delta \varphi_{I}=\left(\arctan I_{\alpha} / I_{\beta}\right)^{\prime}-\left(\arctan I_{\alpha} / I_{\beta}\right)\end{array}\right.$

Where $\left(\arctan U_{\alpha} / U_{\beta}\right)^{\prime}$ and $\left(\arctan U_{\alpha} / U_{\beta}\right)$ are electrical angles of previous and present sample time within range of $[0,2 \pi]$.

Then, confidence coefficient of parameters for volts and currents are calculated in equation (6). Here, the sum of $B_{U}$ and $B_{I}$ value ( 0 or 1$)$ is obtained at each sample time and the confidence proportion $T I_{(U)}$ and $T I_{(I)}$ is evaluated as below.

$$
\left\{\begin{array}{l}
T I_{(U)}=\frac{\sum_{i=1}^{m} B_{U}}{m} \\
T I_{(I)}=\frac{\sum_{i=1}^{m} B_{I}}{m}
\end{array}\right.
$$

Where $m$ is total sample points during a fixed sample time.

The calculation of motor mechanical speed depends $n_{\text {mech }}$ on confidence coefficients of volts and currents as well as the sum of change rate of electrical angle. Two paths of parameters feature extraction that calculates motor mechanical speed are finally merged together in equation (7), $Q F_{(U)}$ and $Q F_{(I)}$ are set to 2. When confidence coefficients of volts and currents 
$\left(T I_{(U)}\right.$ and $\left.T I_{(I)}\right)$ is not high enough and within confidence range $\left\{0<\left[T I_{(U)}, T I_{(I)}\right]<T I_{(\text {min })}\right\}$, rotary transformer angle is used to calculate motor speed instead of electrical angle related with parameters feature of volts and currents according to the process in fig.3, $Q F_{(U)}$ and $Q F_{(I)}$ are set to 1 at this condition.

$$
n_{\text {mech }}=\frac{\sum_{i=1}^{m} \Delta \varphi_{U} \cdot T I_{(U)}+\sum_{i=1}^{m} \Delta \varphi_{U} \cdot T I_{(I)}}{N_{p} \cdot m \cdot \Delta t \cdot\left[T I_{(U)}+T I_{(I)}\right]}
$$

Where $N_{p}$ is number of pole-pairs for motor, $\Delta t$ is time interval per each sample point.

On the other hand, average power $P_{\text {ave }}$ during a sample time is calculated by deviation correction of volts and currents in equation (8) as below.

$$
P_{\text {ave }}=\frac{\sum_{i=1}^{m}\left(U_{u} \cdot I_{u}\right)_{u p d}+\left(U_{v} \cdot I_{v}\right)_{u p d}+\left(U_{w} \cdot I_{w}\right)_{u p d}}{m}
$$

\section{Torque Estimation and Determination}

In order to ensure the validity of torque estimation, quality factor $Q F$ is a key point to decide final torque estimation as equation (9). $Q F_{(U)}$ and $Q F_{(I)}$ from feature extraction of different parameters are usually different each other due to interference level, stability as well as failure probability for three-phase parameters. Therefore, the minimal value between $Q F_{(U)}$ and $Q F_{(I)}$ is proper quality factor to maintain reliability of motor torque estimation.

$$
Q F=M I N\left[Q F_{(U)}, Q F_{(I)}\right]
$$

There are three states for $Q F$ to estimate motor torque as below.

When $Q F$ is equal to 0 , motor torque estimation is set to 0 . Because the feature extraction of parameters is invalid to estimate motor torque.

When $Q F$ is equal to 1, the confidence coefficient of parameters is not too high to support torque estimation, therefore it is necessary to do bench test and find effective alternative solution to estimate motor torque by looking up table of motor currents square related with actual torque in fig.4. Additionally, torque direction is decided by motor average power, copper loss as well as motor mechanical speed in

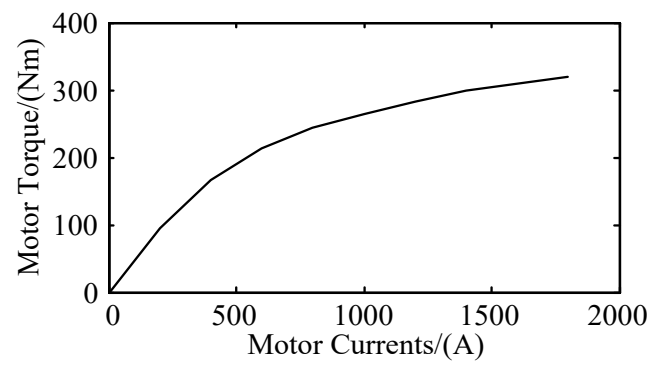

equation (10).

$$
\left\{\begin{array}{c}
\operatorname{sign}\left(T_{\text {mot }}\right)=\operatorname{sign}\left(\frac{P_{\text {ave }}-I_{\text {ave }}^{2} \cdot R_{\text {ave }}}{n_{\text {mech }}}\right) \\
I_{\text {ave }}^{2}=\frac{\sum_{i=1}^{m} I_{u}^{2}+I_{v}^{2}+I_{w}^{2}}{m} \\
R_{\text {ave }}=\frac{R_{u}+R_{v}+R_{w}}{3}
\end{array}\right.
$$

Where $\operatorname{sign}\left(T_{m o t}\right)$ is the direction sign of motor torque estimation. $R_{\text {ave }}$ is average internal resistance of stator winding for three-phase. $R_{u}, R_{v}, R_{w}$ are internal resistance of stator winding for three-phase respectively.

When $Q F$ is equal to 2, the confidence coefficient of parameters is high enough to estimate motor torque in equation (11). There are two operation states including driving and regenerating braking, motor torque direction is decided by results sign from equation (11).

$$
\left\{\begin{array}{c}
T_{\text {mot }}=\frac{P_{\text {ave }} \eta_{d}}{n_{\text {mech }}} \\
T_{\text {mot }}=\frac{P_{\text {ave }}}{n_{\text {mech }} \cdot \eta_{g}}
\end{array}\right.
$$

Where $T_{m o t}$ is motor torque estimation. $\eta_{d}$ and $\eta_{g}$ are the efficiency of driving and regenerating braking states respectively.

\section{Failures Diagnosis and Security Protection Strategy}

Driver requirement torque combined with power operation state from VCU analysis is obtained to send to MCU. The requirement of power and economy can be met by reasonable torque control, but abnormal motor driving or braking forces caused by incorrect torque estimation and invalid operation command generates unexpected acceleration or deceleration of EV. Therefore, reasonable fault diagnosis strategy and security protection mechanism are designed to ensure people and motor system into security state before hazards and risks occur [24]-[25].

According to previous description, the failures diagnosis judgement is decided for overrange faults parameters (such as three-phase volts and currents), significant torque deviation as well as torque direction fault and security protection strategy is designed respectively for each failure.

6.1 The solution scheme to overrange fault

When overrange faults for three-phase volts or currents occur, Kirchhoff's law can't reach 
requirement. Invalid parameters feature extraction brings serious hazards for powertrain torque control. Therefore it is necessary to ensure motor driving system comes into security state by controlling low-side or high-side active short circuit for three-phase full bridge circuit. Meanwhile $Q F$ is set to 0 and motor output torque is inhibited.

6.2 The solution scheme to significant torque deviation

Significant torque deviation generates unexpected acceleration or deceleration behavior that brings drivers to serious hazards. Torque deviation range is decided carefully and set reasonably to void unnecessary power shut-off within normal range of torque deviation between motor output torque and VCU requirement torque. The torque deviation exceeding torque limit is considered as a judgement condition of significant torque deviation and active security state within Fault Tolerant Time Interval (FTTI, $\Delta \mathrm{T}_{\mathrm{FTTI}} \leqslant 150 \mathrm{~ms}$ ). When equation (12) reaches to requirement, $\mathrm{QF}$ is set to 0 and motor output torque is inhibited.

$$
\left\{\begin{array}{c}
\Delta T_{d e v} * k>T_{\text {lim }} \\
\Delta T_{d e v}=T_{m o t}-T_{r e q}
\end{array}\right.
$$

Where $T_{\text {req }}$ is VCU requirement torques, $\Delta T_{\text {dev }}$ is torque deviation, $k$ is sign factor of torque direction in Tab.2, $T_{\text {lim }}$ is torque deviation limit for active security state, $t_{0}$ is the beginning of sample time point.

Tab.2 The definition of factor $k$

\begin{tabular}{ccc}
\hline$T_{\text {req }}$ & $\Delta T_{\text {dev }}$ & Sign Factor $k$ \\
\hline$T_{\text {req }} \geq 0$ & $\Delta T_{\text {dev }} \geq 0$ & $k=1$ \\
$T_{\text {req }} \geq 0$ & $\Delta T_{\text {dev }}<0$ & $k=0$ \\
$T_{\text {req }}<0$ & $\Delta T_{\text {dev }}>0$ & $k=0$ \\
$T_{\text {req }}<0$ & $\Delta T_{\text {dev }} \leq 0$ & $k=-1$ \\
\hline
\end{tabular}

\subsection{The solution scheme to torque direction fault}

In order to check torque direction fault, reasonable judgement condition is designed as equation (13). There are three steps as below:

Step (1): Confidence coefficient should be enough high $(Q F=2)$ to ensure the validity of estimation torque direction.

Step (2): Estimation torque direction is obtained by equation (10) and compared with that of VCU requirement torque.

Step (3): When both directions are reverse, security state is active or inactive by judging which is greater between motor torque estimation $T_{m o t}$ and torque limit threshold $T_{\text {dir_lim }}$.

$$
\mathrm{C}=\left\{\begin{array}{c}
\operatorname{sign}\left(T_{\text {req }}\right) !=\operatorname{sign}\left(T_{\text {mot }}\right) A N D \\
\left|T_{\text {mot }}\right| \geq T_{\text {dir_lim }} A N D Q F=2
\end{array}\right\}
$$

Where $T_{\text {dir_lim }}$ is torque limit threshold for direction fault.

According to Fig.5. When motor runs at point A, the direction of torque estimation $\left(a_{2}>0\right)$ is reverse to that of VCU requirement torque $\left(a_{1}<0\right)$, but absolute value $a_{2}$ that brings a lower driving force to wheels is less than positive torque limit $+T_{\text {dir_lim }}$ and there is no risk for EV running, therefore security state is inactive in point $\mathrm{A}$. When it comes into point $\mathrm{B}$, both directions of $b_{1}$ and $b_{2}$ are reverse and absolute value $b_{2}$ that brings a higher driving force to wheels is greater than positive torque limit $+T_{\text {dir_lim }}$, therefore security state is active in point $B$ to ensure driving security. Meanwhile $Q F$ is set to 0 and motor output torque is inhibited.

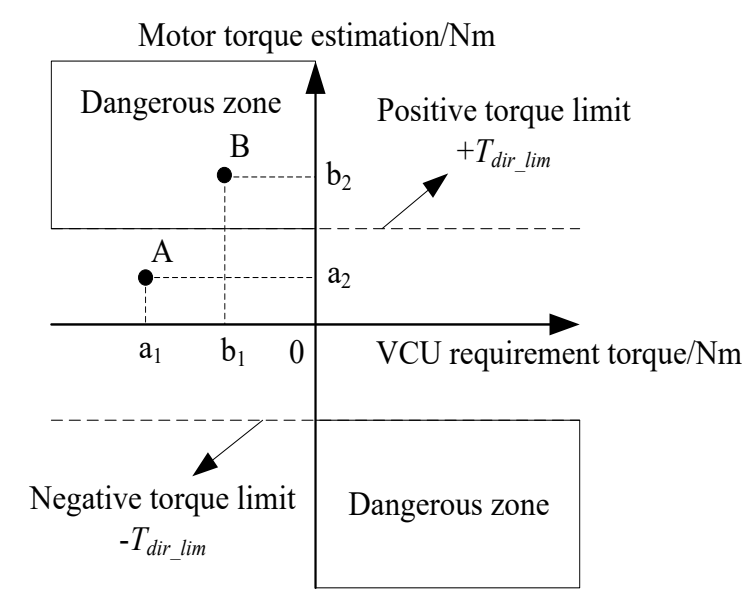

\section{Bench Test}

The model of torque estimation and security control is designed by the environment of MATLAB/Simulink, meanwhile source code is generated and complied by tools of Targetlink and CodeWarrior to hardware. Power and Hardware in Loop (HIL) test bench are built to verify torque estimation accuracy and security control strategy in Fig.6. VCU requirement torques and motor operation mode are sent to MCU by simulator 


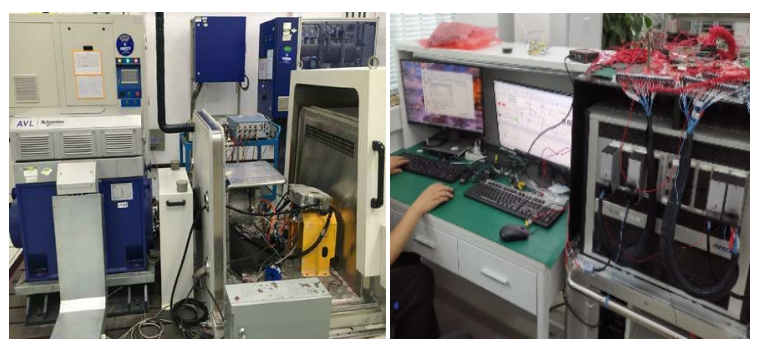

Fig.6 Power and HIL test bench

dspace, feedback signals related with toque estimation and security control are observed by upper computer as a close-loop monitoring.

\subsection{Accuracy verification of estimation torque}

It is necessary to check the accuracy of estimation torque before the rationality of security control strategy is verified. Therefore, estimation torque is compared with actual test torque in whole motor operation range. Power level test results show that estimation torque error is within $\pm 5 \mathrm{Nm}$ according to Fig. 7 and estimation torque proposed in this paper can be considered as actual torque to be applied in torque security control.

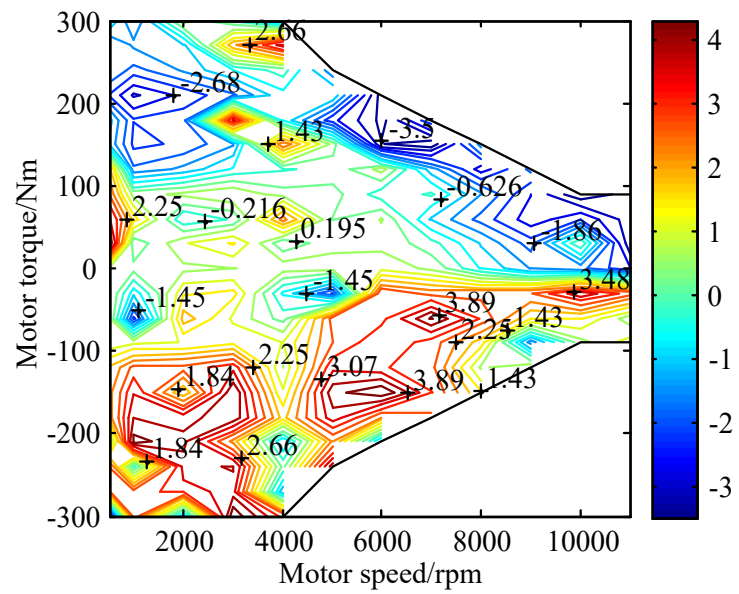

Fig. 7 The error between estimation and actual test torque

\subsection{Security verification of overrange fault}

In order to verify security mechanism of overrange faults, V-phase volts and currents are brought to be overrange by calibration modification respectively. According to Fig. 8, when V-phase volts exceeds upper threshold value $\left(U_{\text {pha_max }}=800 \mathrm{~V}\right)$ at about $62 \mathrm{~s}, \mathrm{QF}$ comes from normal state $(\mathrm{QF}=2)$ to fault latch-state $(\mathrm{QF}=0)$ and Kirchhoff Fault (KF) flag is also latched to
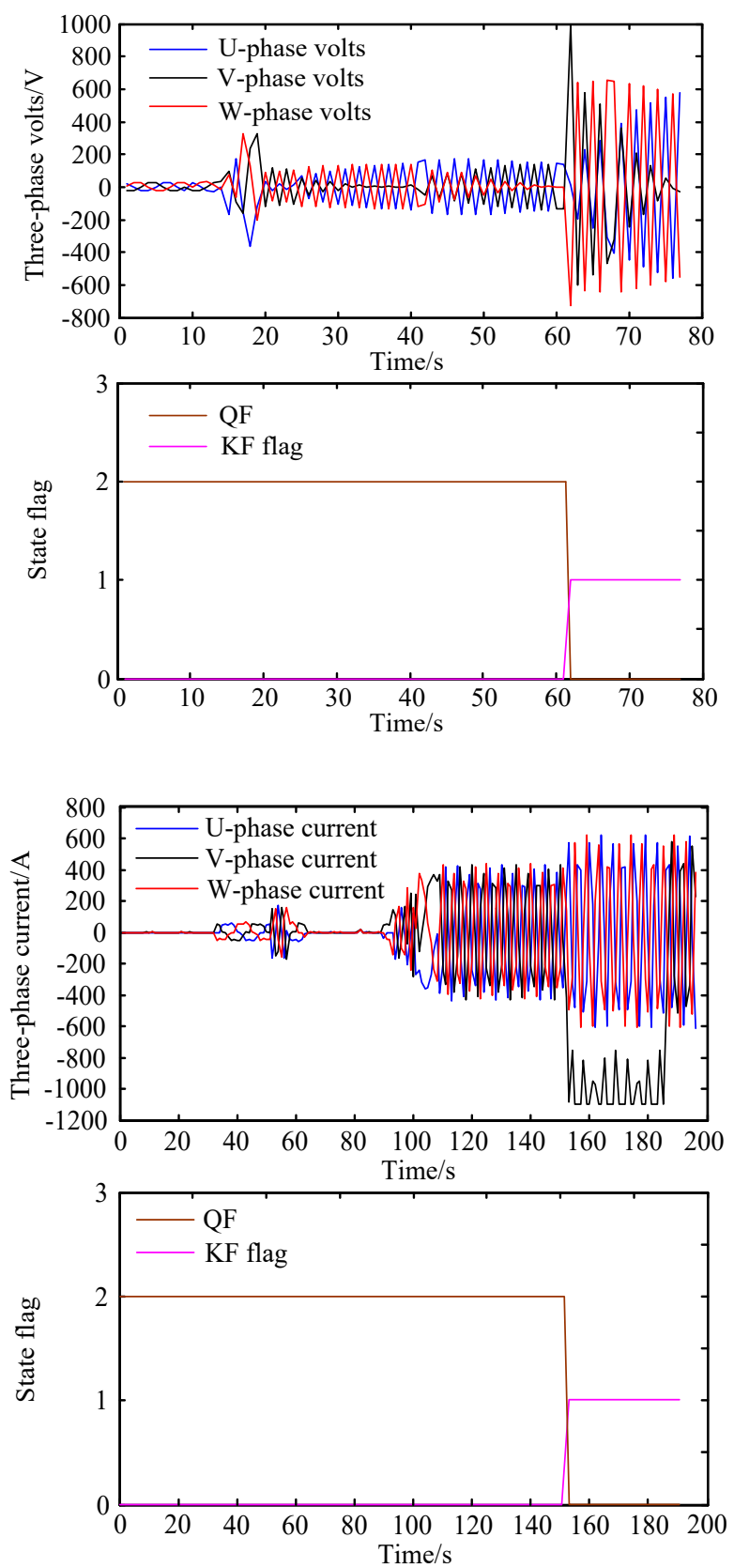

Fig.9 Overrange currents verification of V-phase

1. According to Fig.9, when V-phase currents exceeds upper threshold value $\left(I_{\text {pha_max }}=1000 \mathrm{~A}\right)$ at about $152 \mathrm{~s}$, QF comes from normal state $(\mathrm{QF}=2)$ to fault latch-state $(\mathrm{QF}=0)$ and Kirchhoff error flag is also latched to 1 . Motor actual torque is inhibited to be output at these overrange fault states.

7.3 Security verification of significant torque deviation fault 

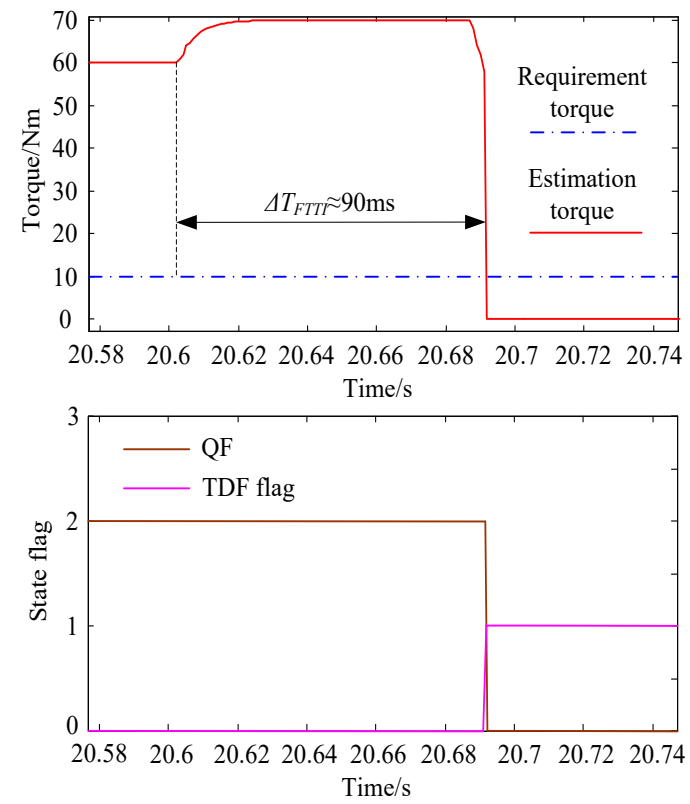

Fig. 10 Torque deviation verification at $2500 \mathrm{rpm} /+10 \mathrm{Nm}$
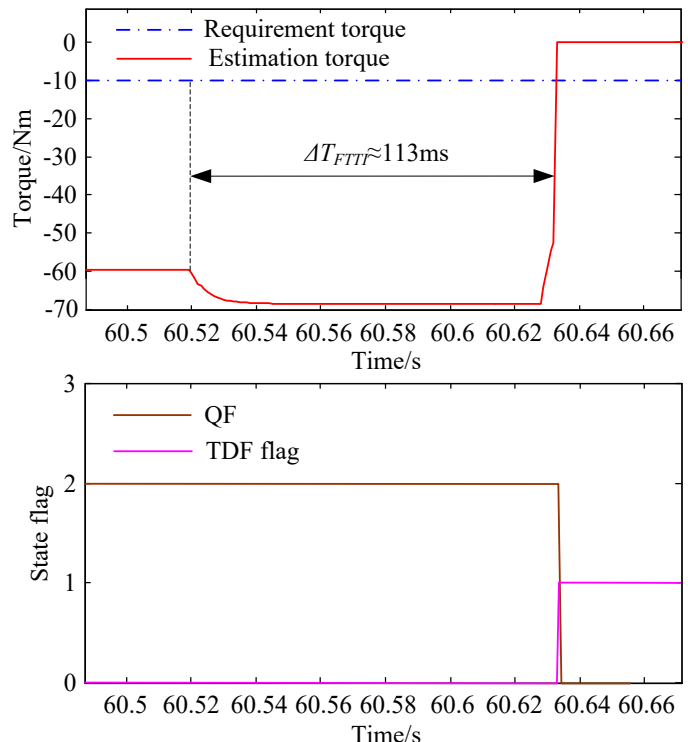

Fig. 11 Torque deviation verification at $1500 \mathrm{rpm} /-10 \mathrm{Nm}$

The security control strategy of positive and negative Torque Deviation Fault (TDF) is verified respectively at operation point $(2500 \mathrm{rpm} /+20 \mathrm{Nm}$, $1500 \mathrm{rpm} /-20 \mathrm{Nm}$ ). Motor runs at operation state $2500 \mathrm{rpm} /+10 \mathrm{Nm}$, when torque deviation between $\mathrm{VCU}$ requirement torque and estimation torque exceeds limit value $\left(\mathrm{T}_{\mathrm{lim}}=50 \mathrm{Nm}\right)$ at about $20.6 \mathrm{~s}, \mathrm{MCU}$ goes into active security state with state flag change ( $\mathrm{QF}=0$, TDE flag=1) and motor torque is cut off within 90ms $\left(<\Delta T_{F T T I}\right)$ in Fig.10. Motor runs at operation state $1500 \mathrm{rpm} /-10 \mathrm{Nm}$, When torque deviation exceeds limit value $T_{l i m}$ at about $60.52 \mathrm{~s}, \mathrm{MCU}$ also comes
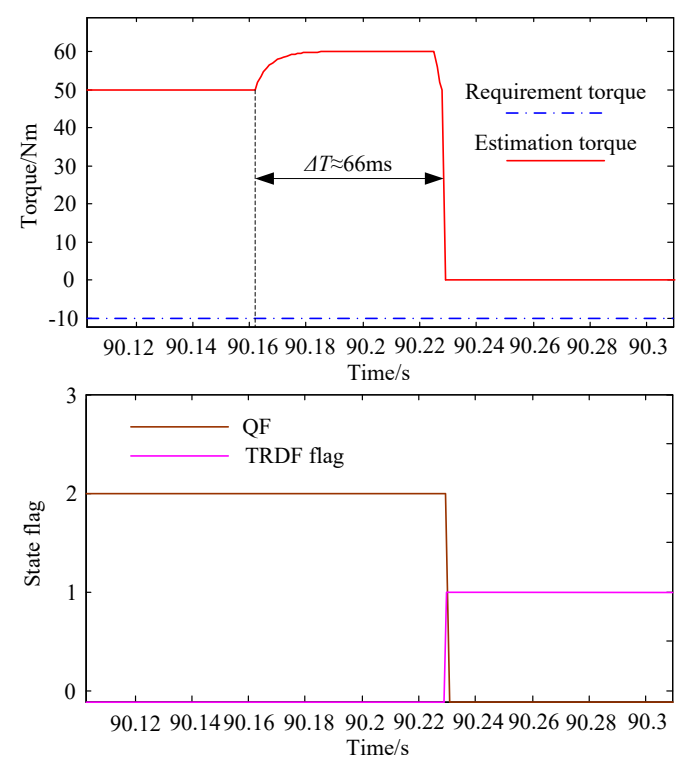

Fig. 12 Torque direction verification at $1500 \mathrm{rpm} /-10 \mathrm{Nm}$
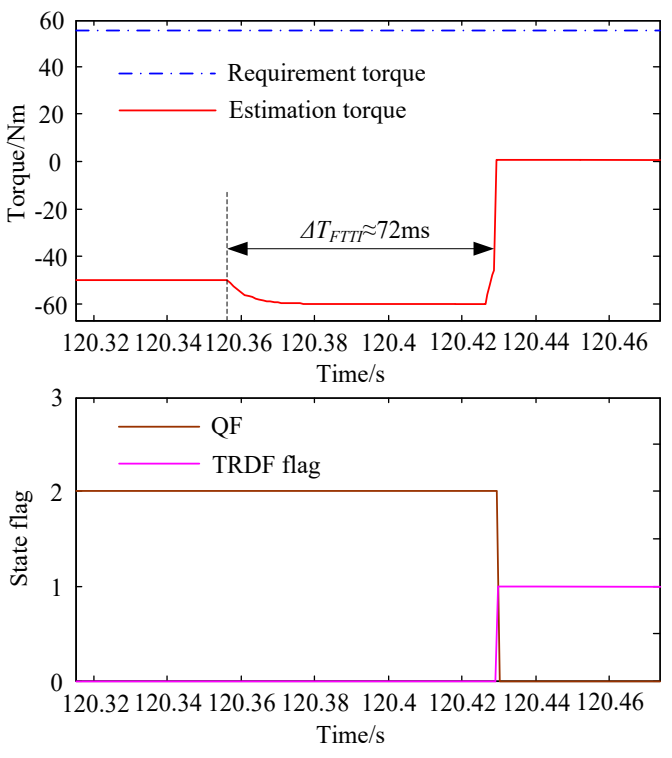

Fig. 13 Torque direction verification at $1500 \mathrm{rpm} /-10 \mathrm{Nm}$

into active security state with state flag change $(\mathrm{QF}=0$, TDE flag=1) and motor torque is cut off within $113 \mathrm{~ms}$ $\left(<\Delta T_{F T T I}\right)$ in Fig. 11.

7.4 Security verification of torque reverse direction fault

The security control strategy of positive and negative Torque Reverse Deviation Fault (TRDF) is verified respectively at operation point $(4000 \mathrm{rpm} /+55 \mathrm{Nm}, 3000 \mathrm{rpm} /-10 \mathrm{Nm})$. When torque direction between VCU requirement torque and estimation torque is reverse at motor operation state $1500 \mathrm{rpm} /-10 \mathrm{Nm}$, and estimation torque exceeds positive torque limit $\left(+T_{\text {dir_lim }}=50 \mathrm{Nm}\right)$ at about 
90.16s, MCU goes into active security state with state flag change $(\mathrm{QF}=0$, TDE flag=1) and motor torque is cut off within $66 \mathrm{~ms}\left(<\Delta T_{F T T I}\right)$ in Fig.12. Motor runs at operation state $1500 \mathrm{rpm} /-10 \mathrm{Nm}$, when the absolute value of estimation torque exceeds that of negative torque limit $-T_{\text {dir_lim }}$ at about $120.36 \mathrm{~s}$, MCU also comes into active security state with state flag change $(\mathrm{QF}=0$, TDE flag $=1)$ and motor torque is cut off within $72 \mathrm{~ms}\left(<\Delta T_{F T T I}\right)$ in Fig. 13.

\section{Conclusions}

1) According to the importance introduction of motor functionality security design for business profits, brand affect and ISO 26262 standard requirements, the development process of motor function security is designed and work item for each step is defined. Functionality security level and security goal are ensured after EV usage scenario and powertrain system HARA are analyzed sufficiently.

2) Three-tier architecture scheme of torque monitoring is designed. Assuming parameter confidence coefficient is considered, feature extraction for three-phase volts and currents is adopted to calculate motor mechanical speed and average power after signal plausibility check and deviation correction is finished. In addition, estimation scheme of motor torque is also decided by confidence coefficient and QF level.

3) Check condition and handling mechanism of each fault are defined. Power and HIL test bench are built to verify the accuracy of motor estimation torque and validity of security control strategy. Test results show that the accuracy of motor estimation torque is within $\pm 5 \mathrm{Nm}$ and it can support the control strategy development of motor functionality security. For overrange fault, significant torque deviation fault as well as torque direction fault, security responding mechanism can bring motor torque to cut off within FTTI and ensure the security of EV driving.

\section{Declarations}

\section{Availability of data and materials}

The datasets used and/or analysed during the current study are available from the corresponding author on reasonable request.

\section{Competing interests}

The authors declare that they have no competing interests.

\section{Funding}

This work was supported by the Changan Multicomponent Integration of Electric Drive System (Grant No. 67612-53010210-030128) and Key Projects of Technological Innovation and Application Development of Chongqing (Grant No. cstc2019jscx-fxydX0028). The role of the funding No. 67612-53010210-030128 support study and collection and Grant No. cstc2019jscx-fxydX0028 support data analysis in writing the manuscript.

\section{Authors' contributions}

PENG Zhiyuan, DU Changhong and ZHOU Anjian design the method of motor torque estimation and security control strategy. LIU Li and CHEN Yang integrate and test software after software building. CHEN Jian and PENG Qianlei verify software validity by building test bench. All authors read and approved the final manuscript.

\section{Acknowledgements}

Not applicable

\section{References}

[1] CHAN C C. The state of the art of electric, hybrid and fuel cell vehicles [J]. Proceedings of the IEEE, 2007, 95(4): 704.

[2] Tao Deng, Zhenhua Su, Junying Li, et al. Advanced Angle Field Weakening Control Strategy of Permanent Magnet Synchronous Motor [J]. IEEE TRANSACTIONS ON VEHICULAR TECHNOLOGY, APRIL 2019. 68(4): 3424-3435.

[3] J. Zheng, Z.Wang, D.Wang, Y. Li, and M. Li. Review of fault diagnosis of PMSM drive system in electric vehicles [C]. Proc. 36th Chinese Control Conf., Jul. 2017: 7426-7432.

[4] Y. Liu, J. Li, Z. Chen, D. Qin, and Y. Zhang. Research on a multi-objective hierarchical prediction energy management strategy for range extended fuel cell vehicles [J]. Journal of Power Sources, 2019. 429: 55-66.

[5] S. M. Lu, A review of high-efficiency motors: Specification, policy, and technology, Renewable Sustain [J]. Energy Rev, Jun. 2016. 59: 1-12.

[6] X. Sun, Z. Shi, G. Lei, Y. Guo, and J. Zhu. Analysis and design optimization of a permanent magnet synchronous motor for acampus patrol electric vehicle [J]. IEEE Transactions on Vehicular Technology, 2019. 68(11): 
10535-10544.

[7] S. M. Lu, A review of high-efficiency motors: Specification, policy, and technology. Renewable Sustain [J]. Energy Rev., Jun. 2016. 59: 1-12.

[8] Z. Rezvani, J. Jansson, and J. Bodin. Advances in consumer electric vehicle adoption research: A review and research agenda [J]. Transp. Res. Part D, Jan. 2015. 34: 122-136.

[9] B. Boazzo and G. Pellegrino, Model-based direct flux vector control of permanent-magnet synchronous motor drives $[\mathrm{J}]$. IEEE Trans. Ind. Appl., Feb. 2015. 51(4): 3126-3136.

[10] ISO/WD 26262. Road Vehicles-Functional Safety [S]. Geneva: International Organization for Standardization, 2011.

[11] ZHAO Zhenglan. Torque Management Safty Concept and Torque Monitoring Model for Pure Electric Vehicles [J]. Chinese Journal of Automotive Engineering, 2018. 8(3): 229-234.

[12] WU Zhihong, LU Ke, ZHU Yuan. Analysis of Active-Short-Circuit of Permanent Magnet Synchronous Motor in Electric Vehicles [J]. Journal of TongJi University (Natural Science), 2018, 46(9): 1288-1305.

[13] Song Peng, Motor Control System and HIL Test Development Based on Functional Safety [D]. Harbin Institute of Technology, 2018.

[14] R. R. Sabbella, M. Arunachalam. Functional Safety Development of Motor Control Unit for Electric Vehicles [C]. IEEE Transportation Electrification Conference (ITEC-India), 2019.

[15] ZHUANG X M, ZHANG Q. Research on Design of the Motor Drive System in Electric Vehicle Based on ISO 26262 [J]. Automobile Parts. 2016(12): 18-21.

[16] BAGALINI E, SINI J, REORDA M S, et a1. An automatic approach to perform the verification of hardware designs according to the ISO 26262 functional safety standard [C] //2017 $18^{\text {th }}$ IEEE Latin American Test Symposium. Cundinamarca Bogota, 2017.

[17] ISO/WD 26262. Road Vehicles-Functional Safety [S]. Geneva: International Organization for Standardization, 2011.

[18] Birch J, Rivett R, Habli I, et al. Safety Cases and Their Role in ISO 26262 Functional Safety Assessment [C]. International Conference on Computer Safety, Reliability and Security, 2013: 154-165.

[19] Wang Wei, Development and Implementation of Vehicle
Controller Based on Functional Safety for Electrical Vehicle [D]. Hunan University, 2018.

[20] SAE J2980, Considerations for ISO 26262 ASIL Hazard Classification [S]. SAE international, 2015.

[21] Takahashi S, Nakamura H, Hasegawa M. Examination of the Validity of Connections between MSILs and ASILs in the Functional Safety Standard for Motor Vehicles [J]. SAE International Journal of Engines, 2015(9): 466-472.

[22] WU X P, LIU F, XIONG L, et a1. Analysis of Impact of PMSM Failure on the Safety of EV under ISO 26262 [J]. Automotive Technology, 2013(2): 13-18.

[23] Standardized E-GAS Monitoring Concept for Gasoline and Diesel Engine Control Units [S]. Version 6.0. EGAS Workgroup, 2015.

[24] Wu Lixun, Chen Jianming, Chen Lei, et a1. Research on the System Architecture of EV Motor Control Unit Based on Functional Safety [J]. Control and information Technology, 2018(3): 1-5.

[25] LIDKI D R, SAEED U, CHENG Siwei. Torque Monitoring System and Method: CN104682813A [P]. 2015-06-03. 
Figures

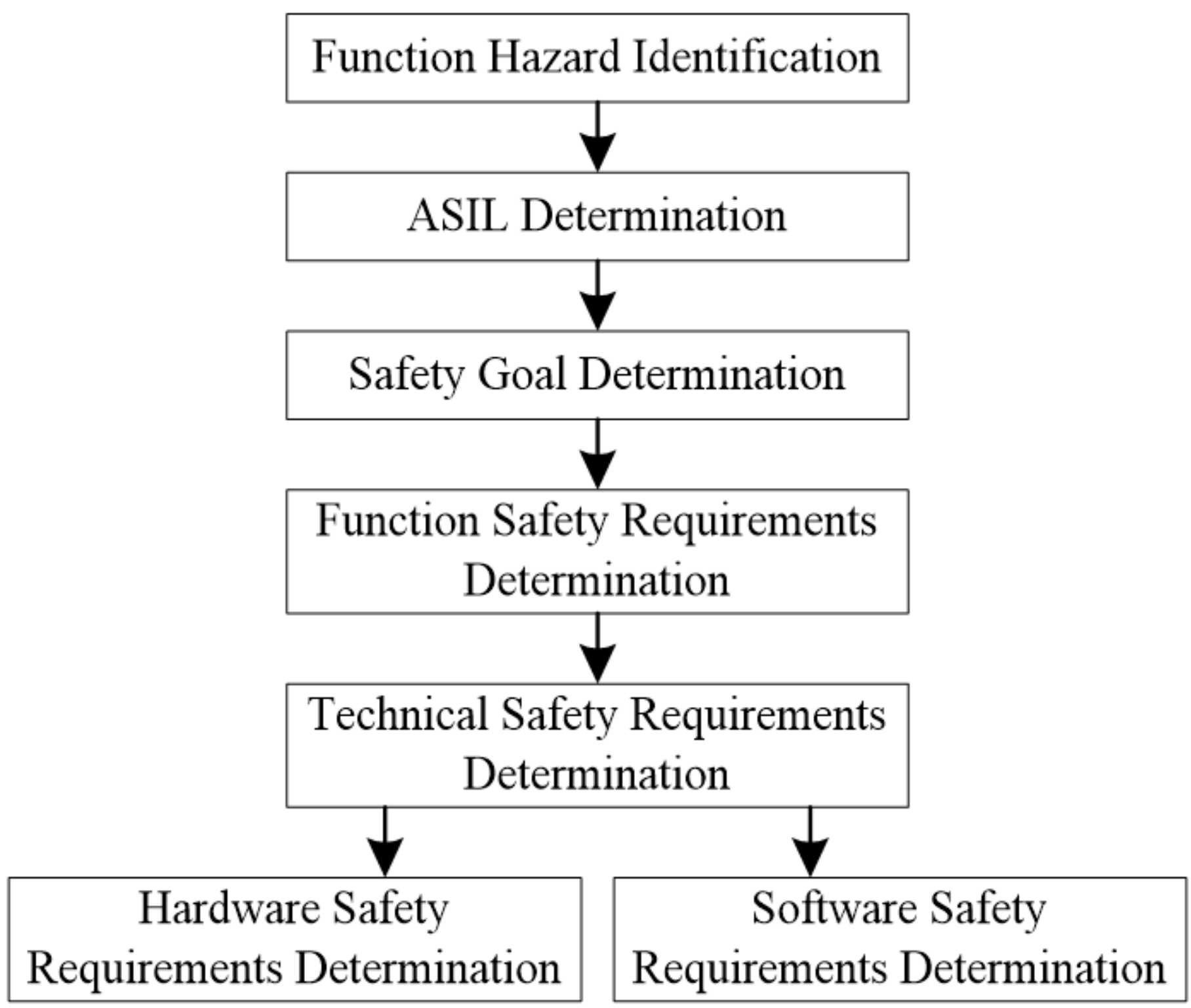

Figure 1

The process of function security development 


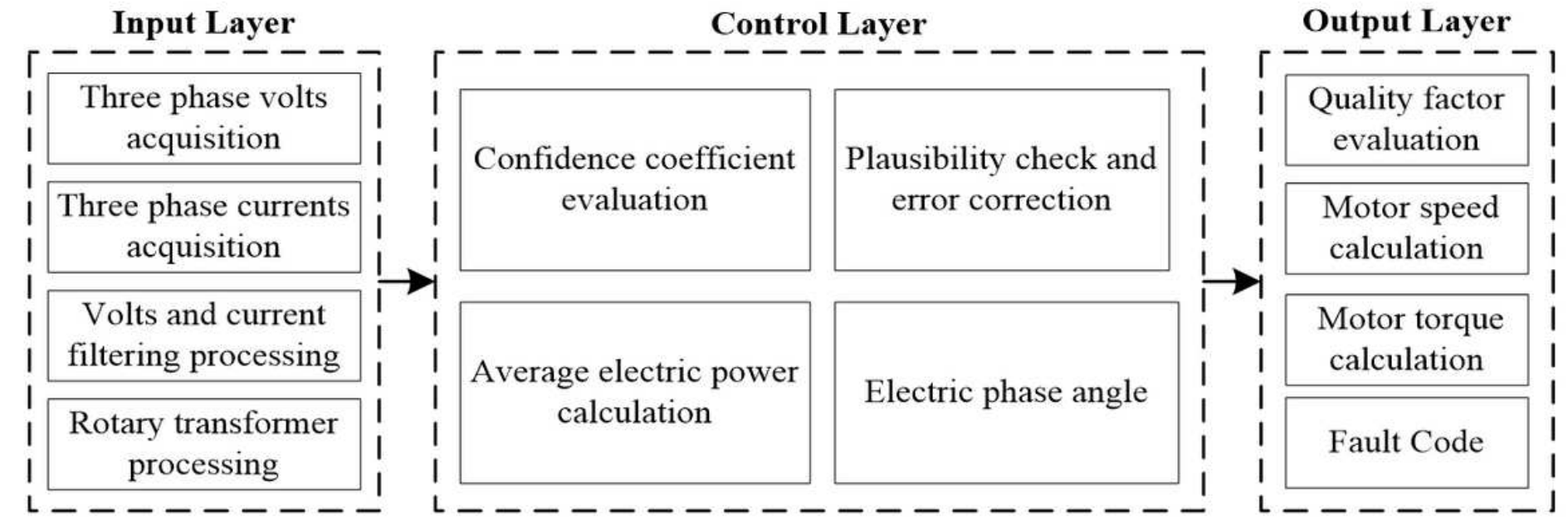

Figure 2

The architecture scheme of torque monitoring

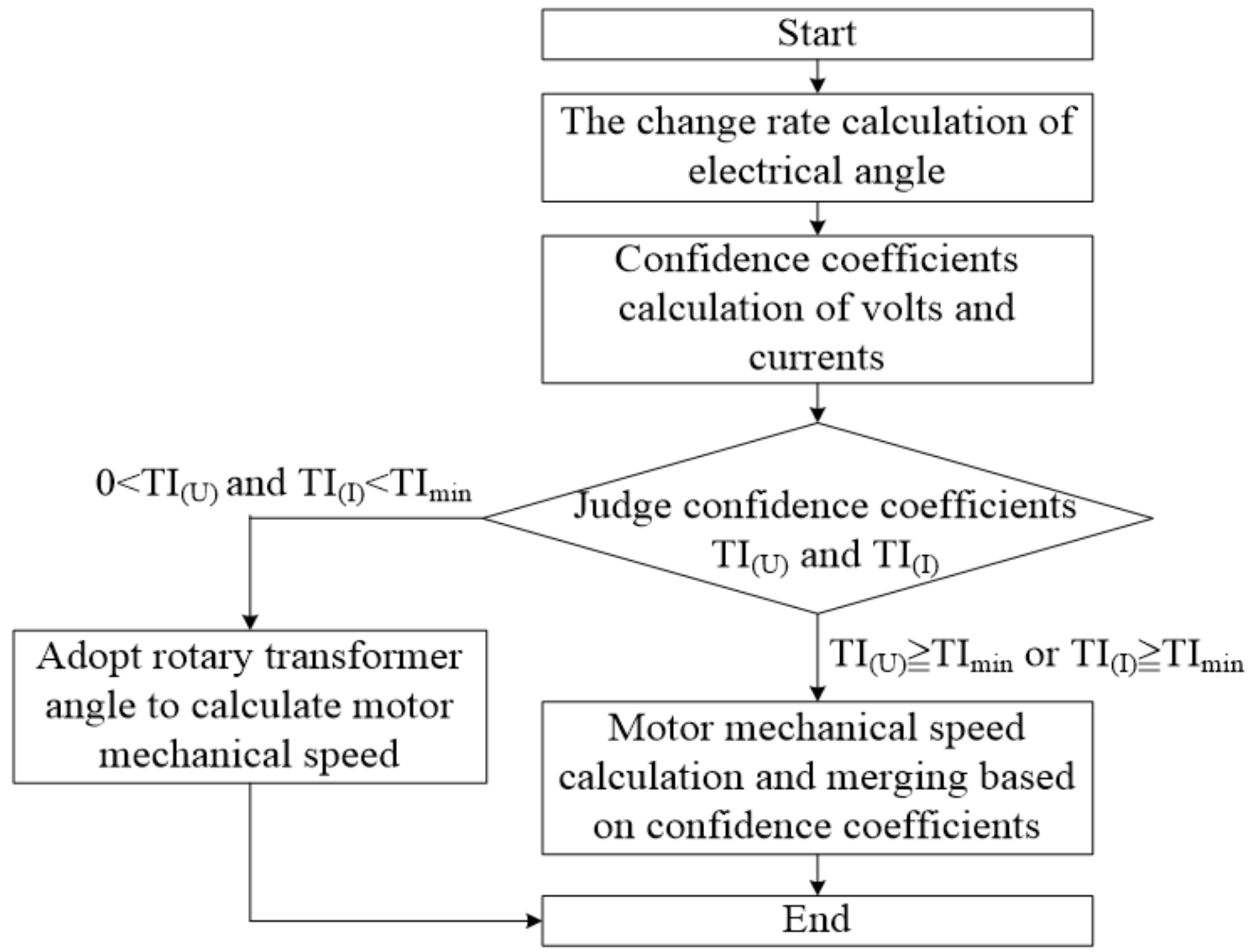

Figure 3 
The calculation process of motor mechanical speed

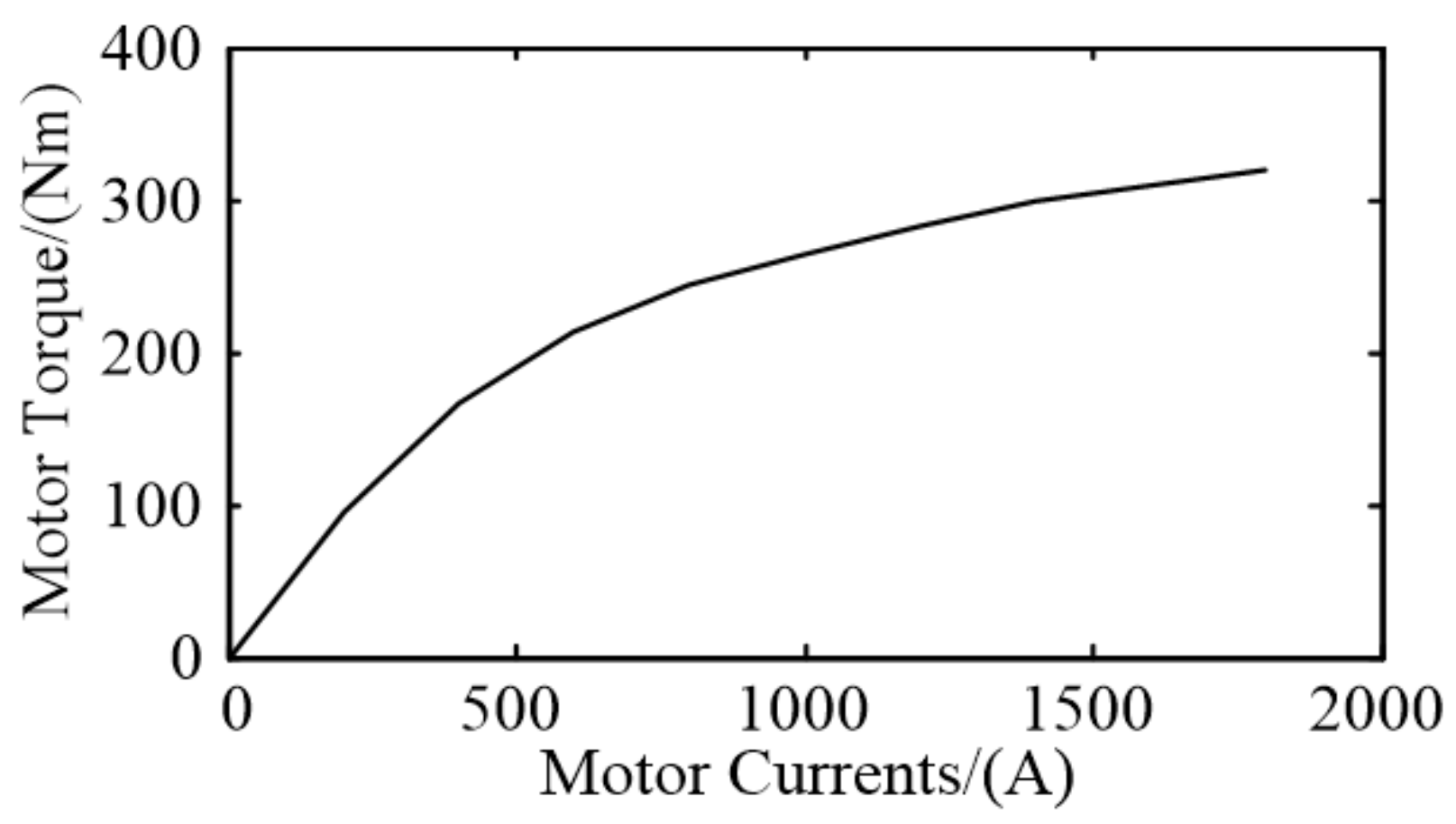

Figure 4

The relationship of motor currents and actual torque 
Motor torque estimation/ $\mathrm{Nm}$

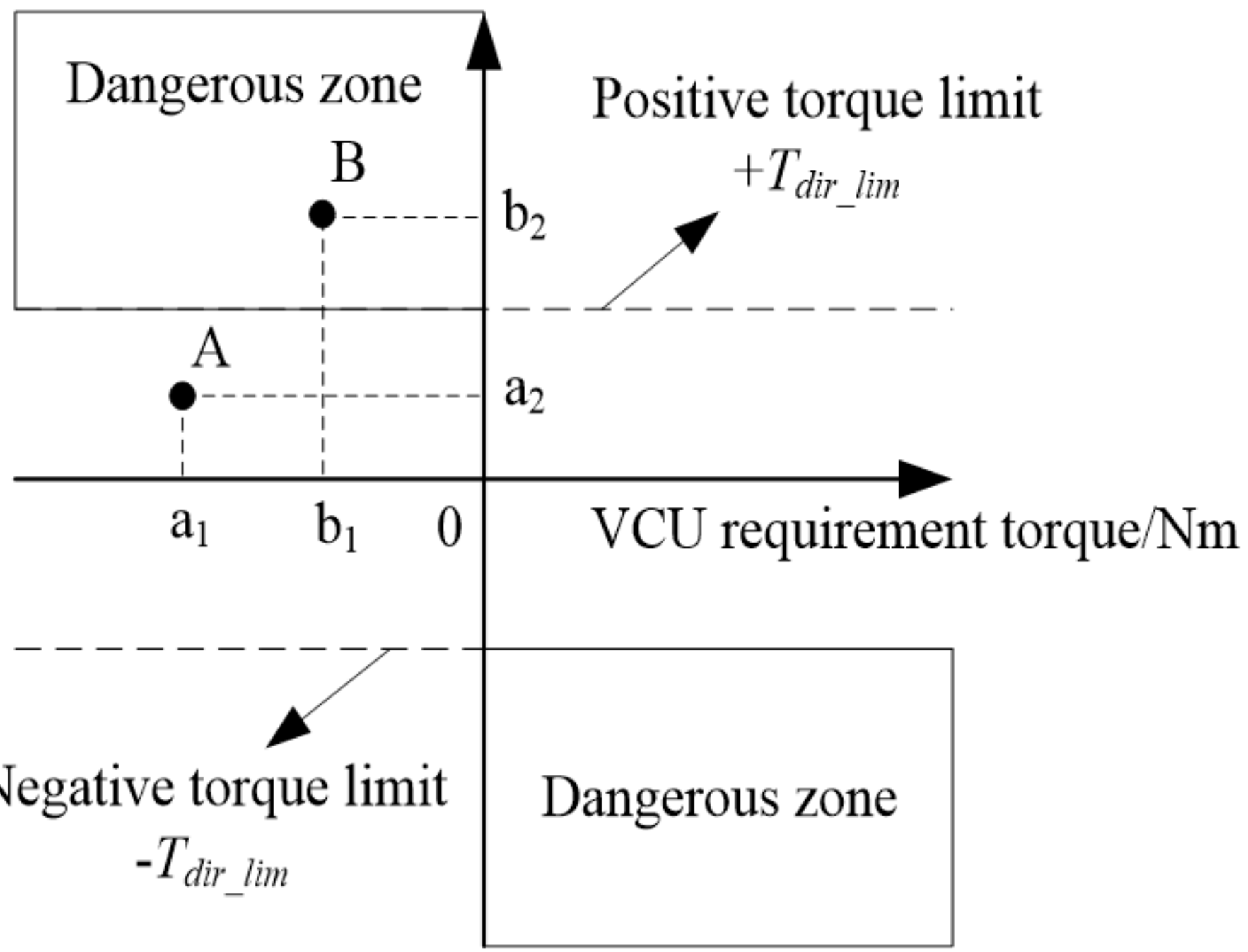

Figure 5

Torque direction monitoring scheme 


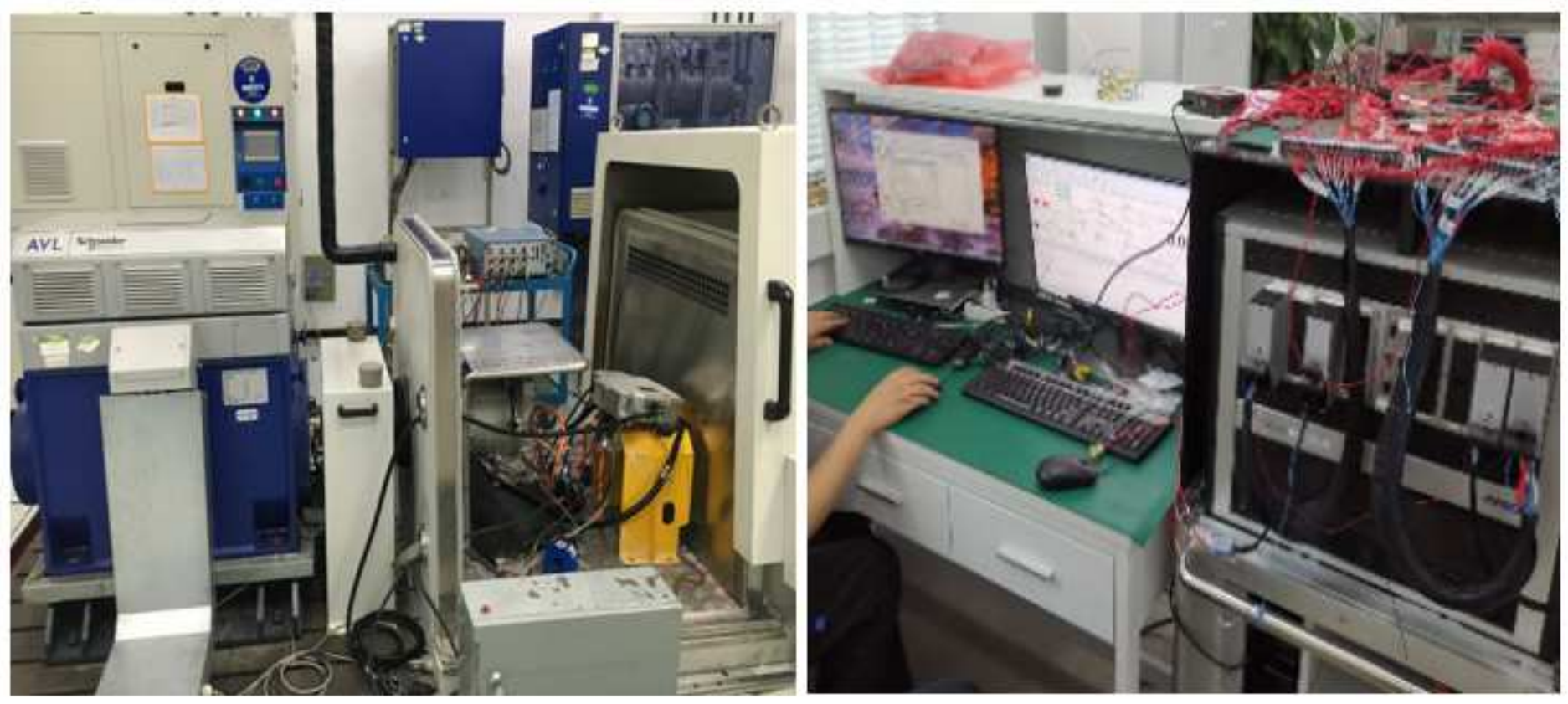

Figure 6

Power and HIL test bench 


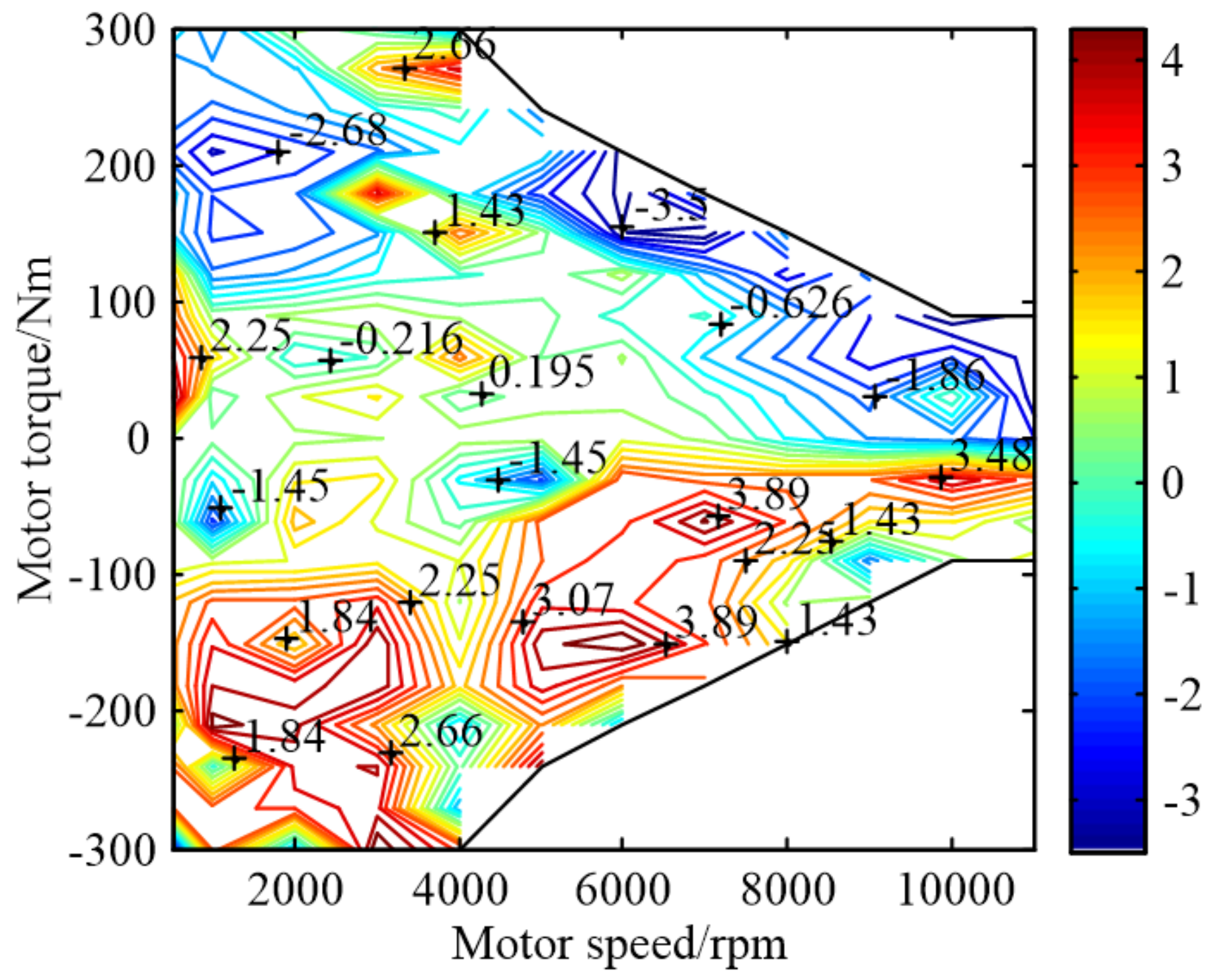

Figure 7

The error between estimation and actual test torque 

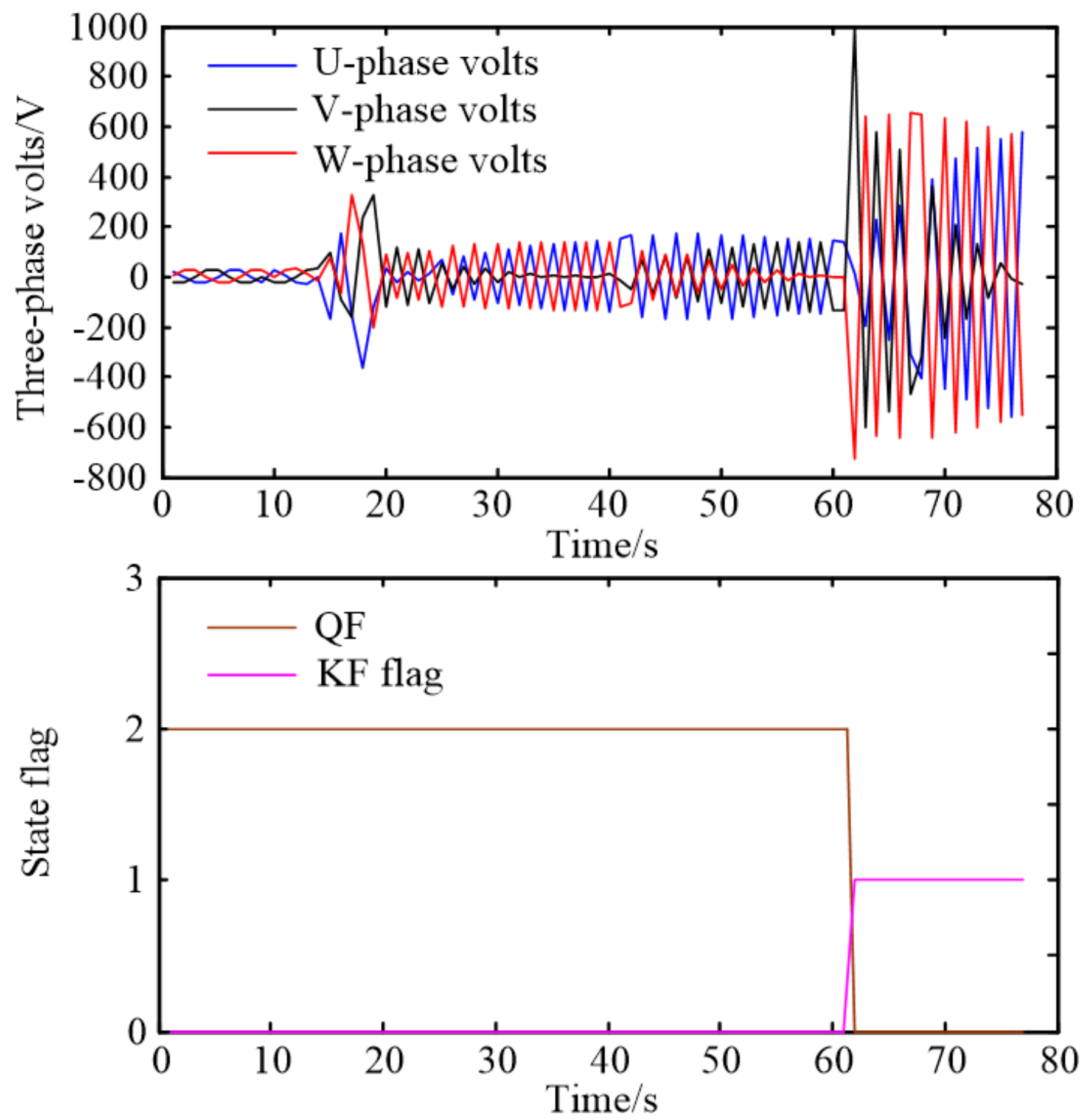

Figure 8

Overrange volts verification of V-phase 

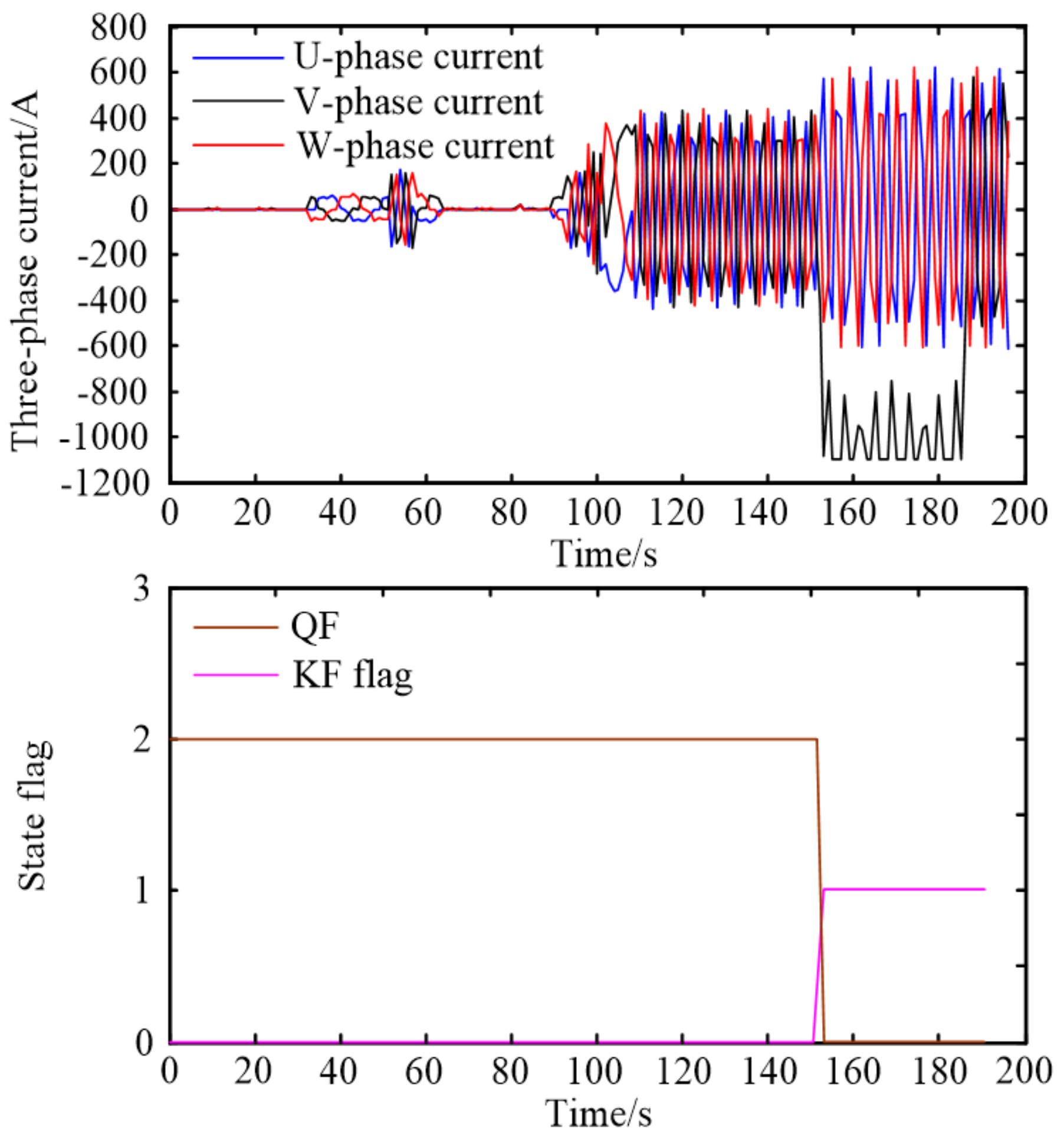

Figure 9

Overrange currents verification of V-phase 

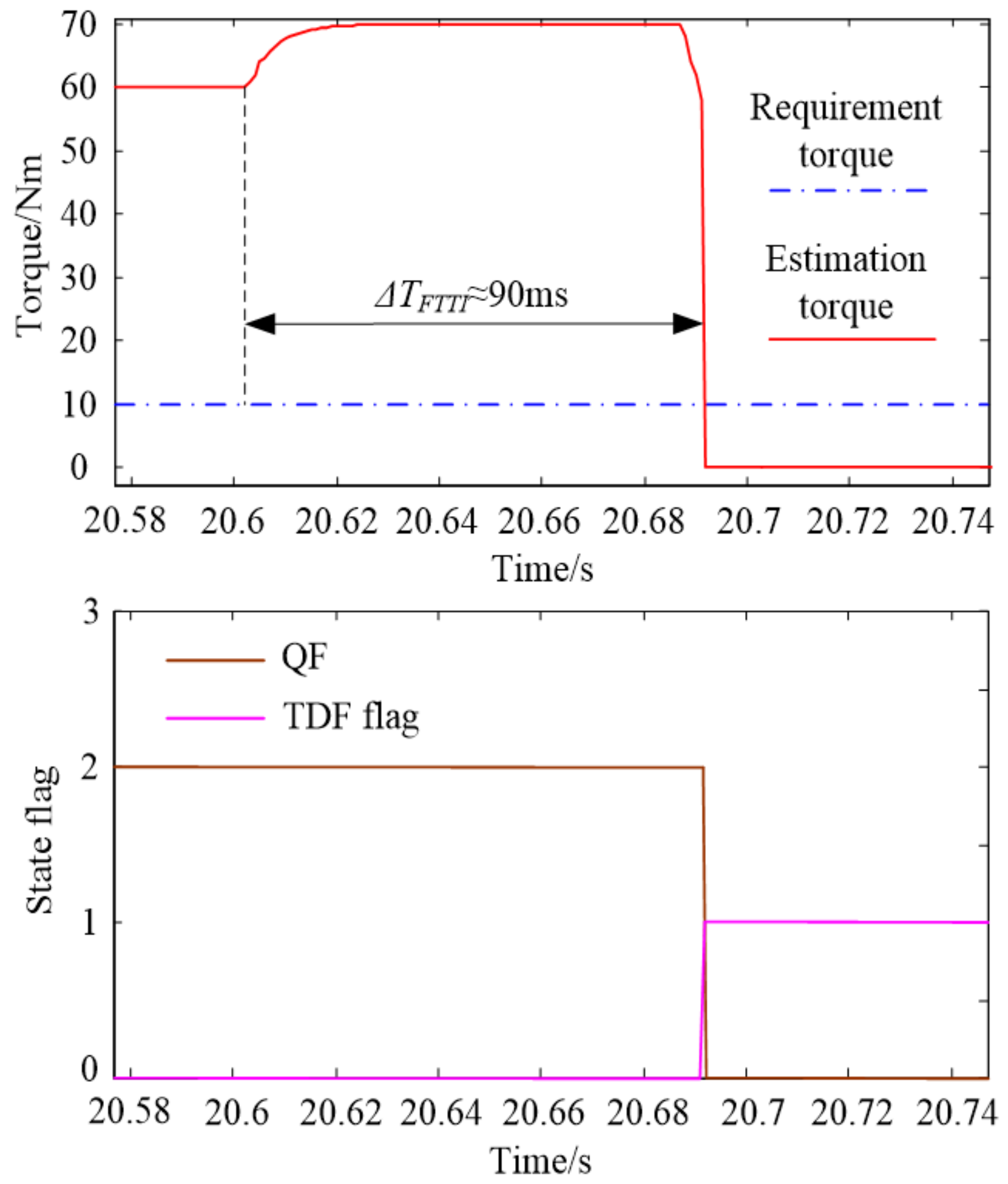

Figure 10

Torque deviation verification at $2500 \mathrm{rpm} /+10 \mathrm{Nm}$ 

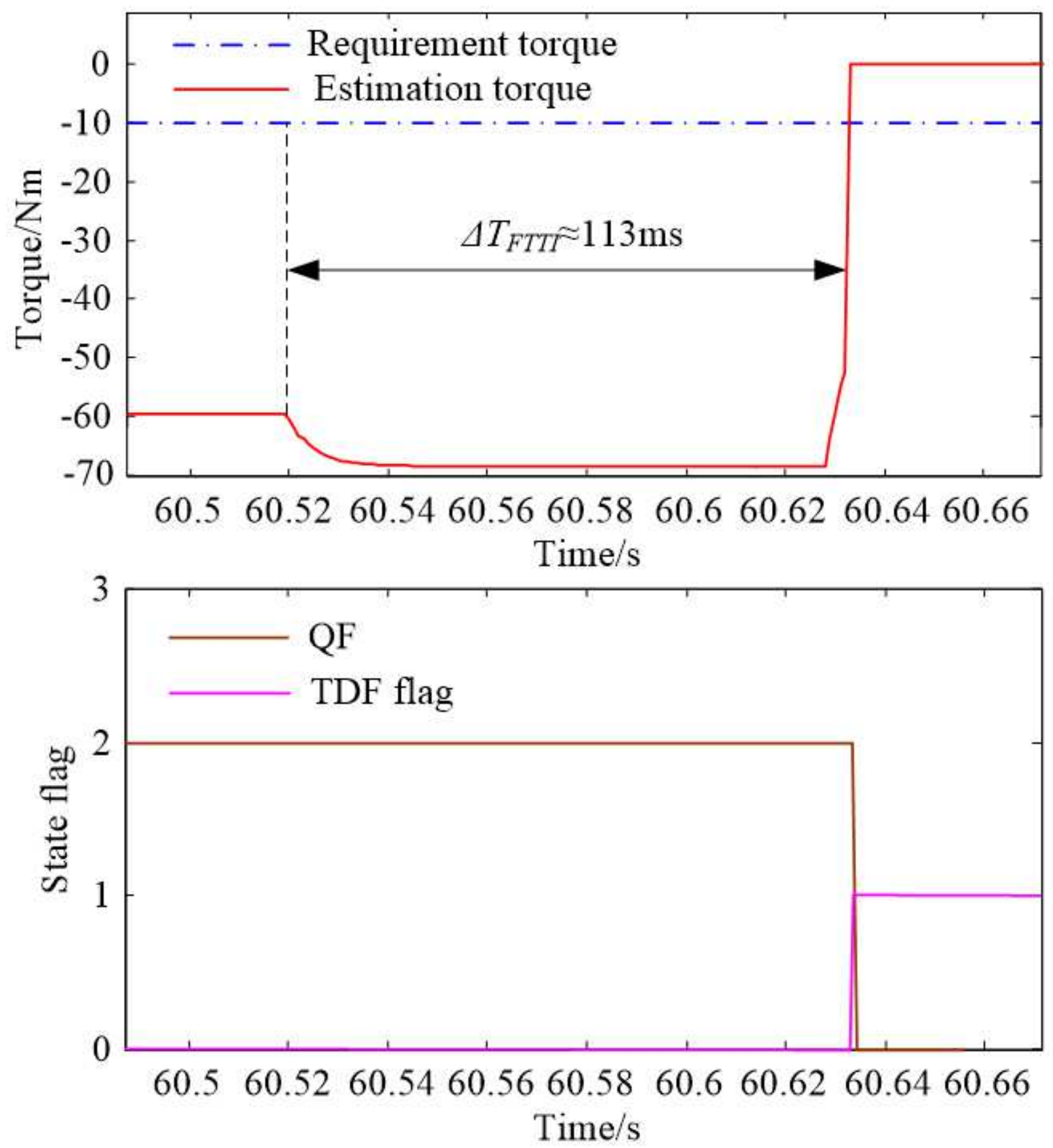

Figure 11

Torque deviation verification at $1500 \mathrm{rpm} /-10 \mathrm{Nm}$ 

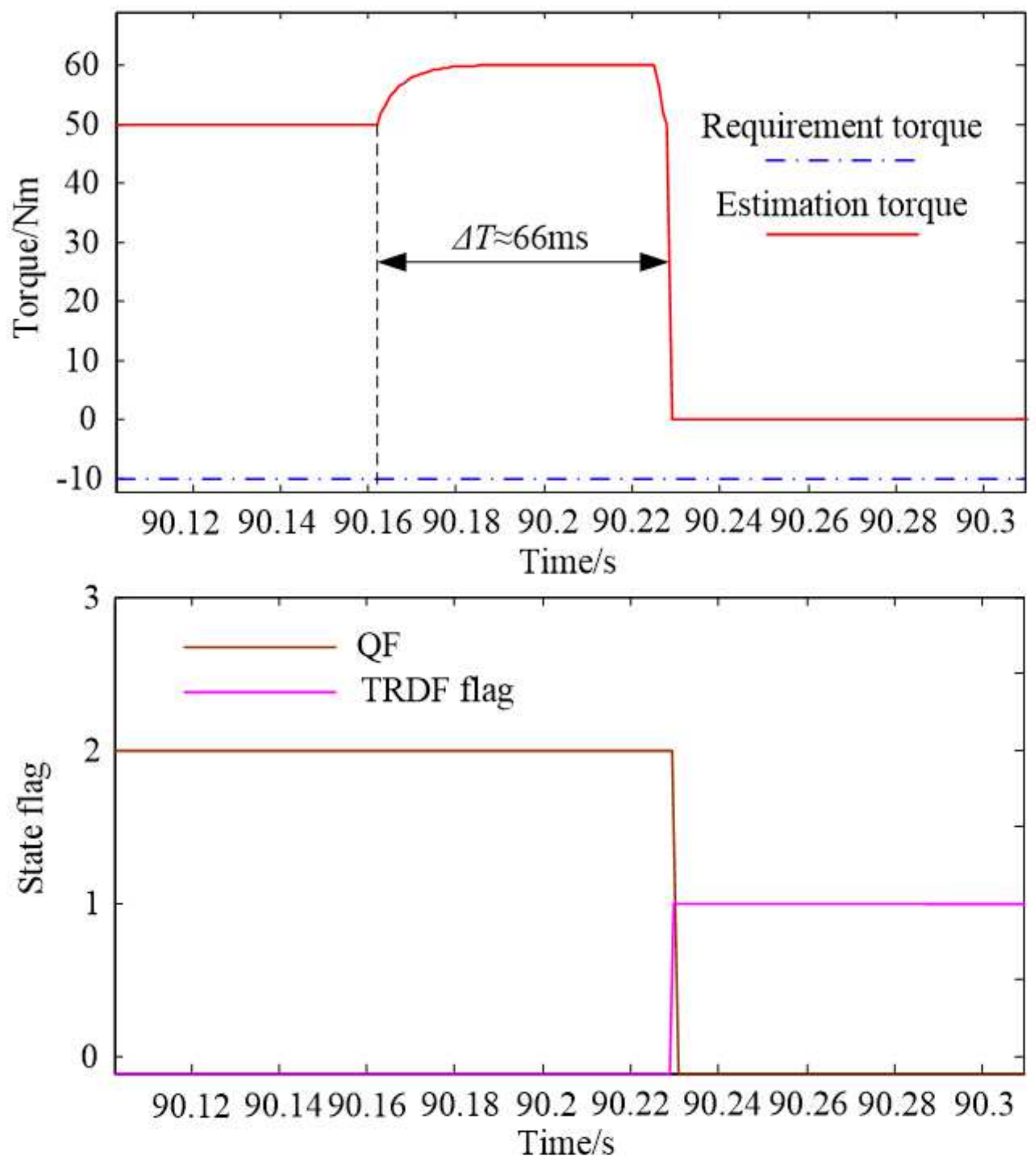

Figure 12

Torque direction verification at 1500rpm/-10Nm 

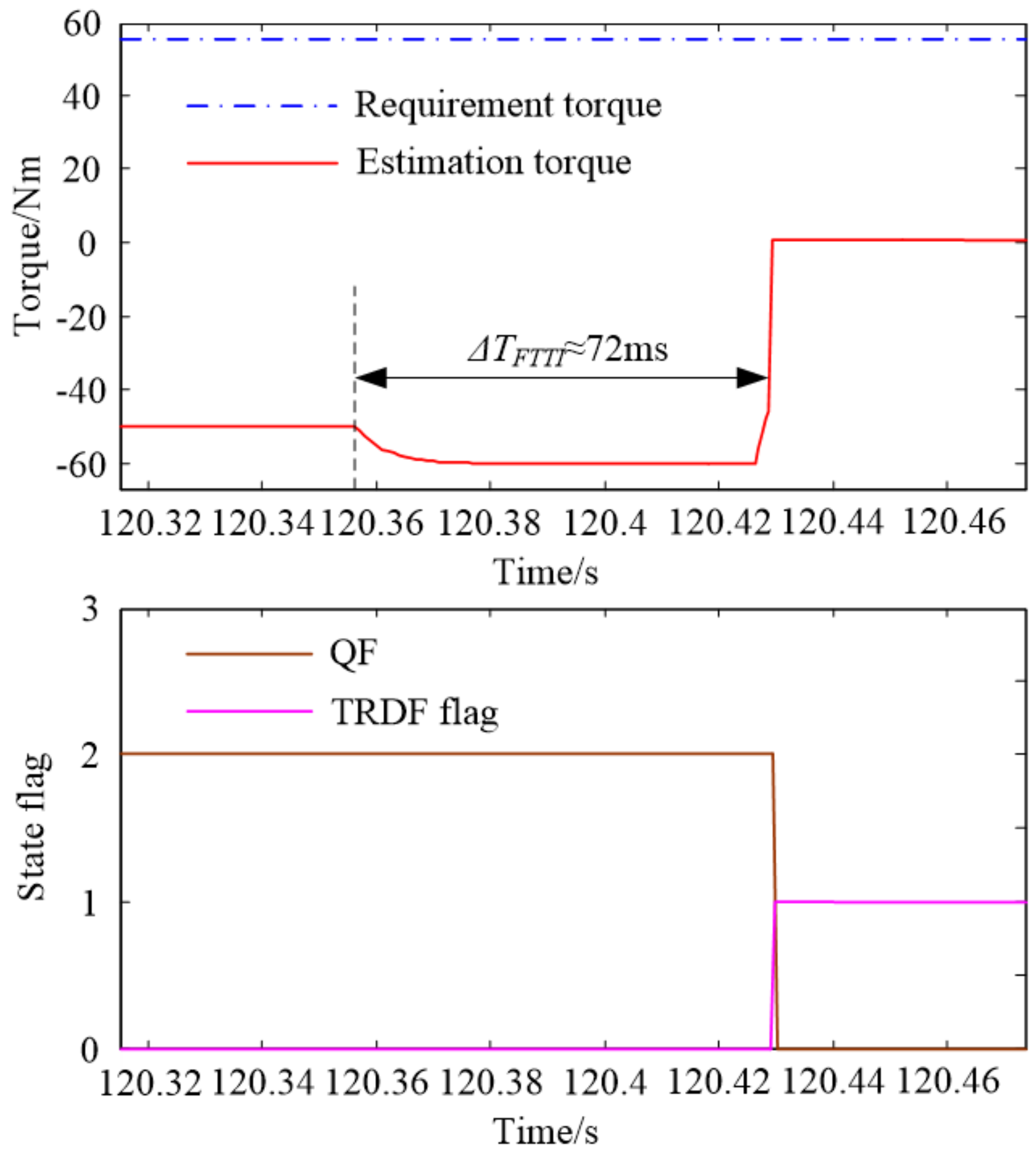

Figure 13

Torque direction verification at $1500 \mathrm{rpm} /-10 \mathrm{Nm}$ 